\title{
Microstructural Characterization on AISI H13 Nitrided After a Heat Treatment
}

\author{
M. A. Doñu Ruiz ${ }^{*}$, N. López Perrusquia ${ }^{1}$, V. J. Cortes Suarez², M. G. Buenrostro Arvizu² and J. A. \\ García Sánchez ${ }^{2}$ \\ ${ }^{1 .}$ Grupo Ciencia e Ingeniería de Materiales, Universidad Politécnica del Valle de México, Tultitlan, \\ Estado de México. México. \\ 2.Área de Ciencia de los Materiales, Universidad Autónoma Metropolitana Unidad Azcapotzalco, \\ Ciudad de México, México. \\ * Corresponding author: marckdr_69@hotmail.com
}

The AISI H13 hot work tool steel is important industrial steel which is used in hot working applications such as forging and die casting moulds. However, a component structure fails at unespected time and the failures are due to wear and fatigue [1]. Heat treatments (quenching and tempering) and thermochemical treatment can be used to improve the surface [2]. Nitriding is a thermochemical treatment consisting of the diffusion of nitrogen in metal alloys, in order to improve their surface mechanical properties, hardness, wear resistance, fatigue resistance and corrosion resistance $[3,4]$. In this study, the microstructure obtained in a steel AISI H13 nitrided at different times by salt bath after a heat treatment is analyzed.

Commercial samples of AISI H13 steel with dimensions of 10x50x5 mm and then ground up to 1200 grit surface finish before surface treatment. Heat treatment (quenching and tempering) and salt bath (TENIFER ${ }^{\circledR}$ process) were applied to AISI H13 steel. Samples were austenized in a vacuum furnace at a temperature of $1283 \mathrm{~K}$ for 90 minutes and cooled with nitrogen to $333 \mathrm{~K}$ and double tempering at 813 $\mathrm{K}$ and $878 \mathrm{~K}$ with $2 \mathrm{~h}$, respectively. After quenching and tempering (QT), the samples QT were nitrided according to "tenifer bath nitriding" at a temperature of $853 \mathrm{~K}$ for $1,1.5$ and $2 \mathrm{~h}$ exposure time. Once the nitriding was over, the samples were left to cool at room temperature. The samples were sectioned by diamond saw and resin embedded, polished using standard metallographic techniques and then etched with $2 \%$ nital solution to reveal their cross-sectional microstructure. The microstructural, morphological and thickness of compounds layers were examined by scanning electron microscopy (JEOL JSM6010LA) with energy-dispersive spectrometry (EDS). Values for the compound layer and diffusion zone (DZ) were obtained as averages over fifty measurements from a fixed references at the surface in each SEM micrograph image. For each nitride condition, such measurements were made on at least four different micrographs. Phases on the compound layers were identified by X-ray diffractometer (XRD) technique by $35 \mathrm{kV}$ and $25 \mathrm{~mA}$ with Cuk $\alpha$ radiation. The diffraction test was under taken by scanning from $20^{\circ}$ to $100^{\circ}$ for phase characterization on the compound layers.

The SEM micrograph of the nitrided cross-section is shown in Figure 1a. The microstructure consists an internal core of tempered martensite and compound layers (magnified SEM image Fig. 1b) at the free surface. The nitride layer consists of a diffusion zone (DZ) with fine precipitates and a compound layers at the surface. Figure 2 shows the EDS area analysis applied in two scanned areas in the sample QTnitrided layer and DZ. A slightly higher peak of nitrogen is obtained in compound layers area because it is an area where nitride is formed. Down below in the diffusion area, a low peak of nitrogen can be found. The main phases found on the surface are iron nitrides which are $\varepsilon-\mathrm{Fe}_{2} \mathrm{~N}(002), \varepsilon-\mathrm{Fe}_{3} \mathrm{~N}(002)$ and $\gamma^{\prime}-\mathrm{Fe}_{4} \mathrm{~N}$ (111) as confirmed by XRD in Figure 3 for QT-nitrided of $1.5 \mathrm{~h}$ sample. The average thicknesses for the compound layers $\left(\gamma^{\prime}-\mathrm{Fe}_{4} \mathrm{~N}+\varepsilon-\mathrm{Fe}_{2-3} \mathrm{~N}\right)$ are $6.58 \pm 0.4,6.95 \pm .89$ and $7.45 \pm 1.2 \mu \mathrm{m}$ and 
for the DZ are $52.11 \pm 1.2,54.5 \pm 1.8$ and $58.55 \pm 1.5 \mu \mathrm{m}$ for $1,1.5$ and $2 \mathrm{~h}$, respectively. The surface of an AISI H13 steel was improved with heat treatment and formation of nitrides on the surfaces for applications in manufacturing subject to wear and fatigue.

\section{References:}

[1] A Persson, S Hogmark, and J Bergström. Journal of Materials Processing Technology 148.1 (2004), p. 108.

[2] H Demir, S Gündüz, and M Akif Erden, The International Journal of Advanced Manufacturing Technology 95.5-8 (2018), p. 2951.

[3] B Matijević, I Kumić, V Alar, International Heat Treatment and Surface Engineering 6 (2012), p. 38.

[4] Totten, G. E. Steel heat treatment: metallurgy and technologies. CRC Press, 2006. p. 536
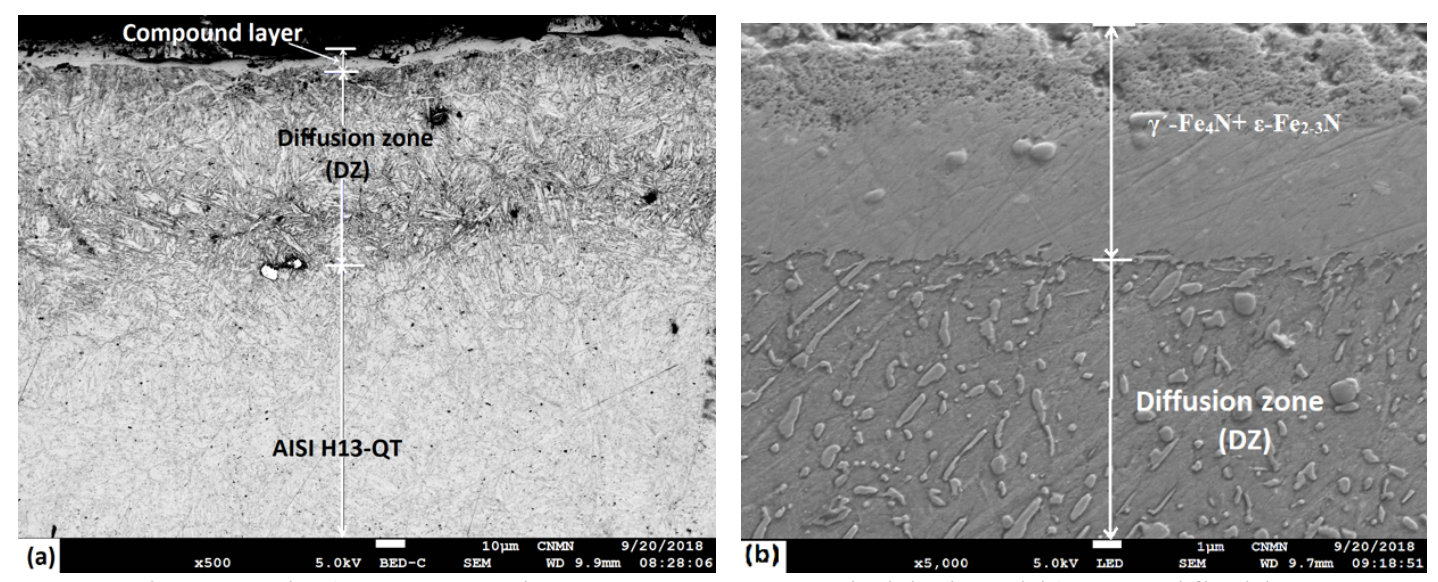

Figure 1. SEM micrograph a) cross section AISI H13 QT-nitrided and b) magnified in compound layer.

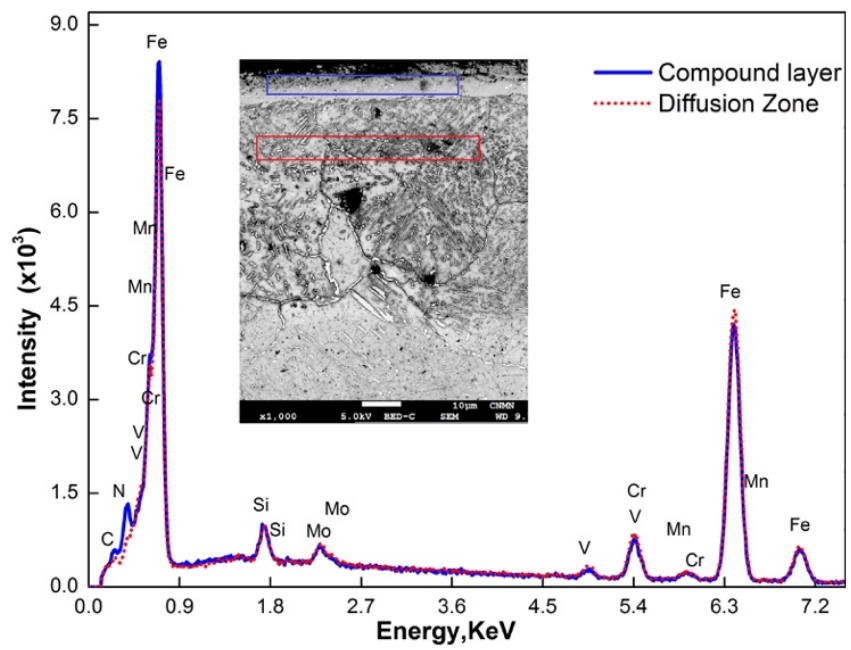

Figure 2. EDS analysis of QT-nitride AISI H13 in the different zone at $853 \mathrm{~K}$ for $1.5 \mathrm{~h}$.

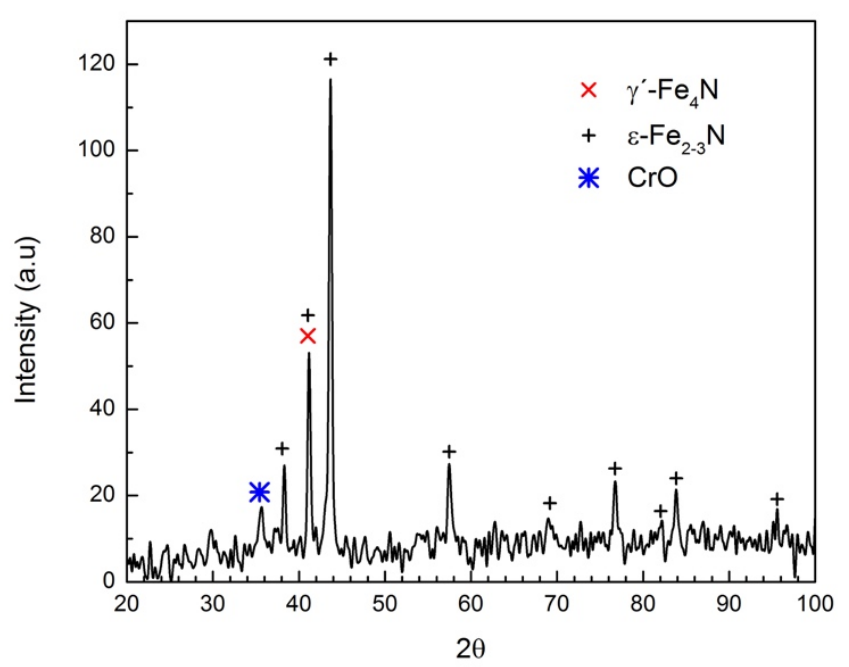

Figure 3. X-ray Diffraction patterns obtained at the surface QT-nitrided on AISI H13-QT. 